\title{
Monomer conversion, dimensional stability, biaxial flexural strength, and fluoride release of resin-based restorative material containing alkaline fillers
}

\author{
Piyaphong PANPISUT and Arnit TONELUCK \\ Faculty of Dentistry, Thammasat University, 99 Moo 18, T. Klong1, A. Klongluang, Pathumthani 12121, Thailand \\ Corresponding author, Piyaphong PANPISUT; E-mail: panpisut@staff.tu.ac.th
}

\begin{abstract}
The aim of this study was to assess monomer conversion, dimensional stability (mass and volume changes), biaxial flexural strength (BFS), and fluoride release of recently developed resin composites containing alkaline fillers (Cention N; CN) compared with resinmodified glass ionomer cements (RMGICs: Riva LC; RL and Fuji II LC; FL), and conventional composite (Z350). FL showed highest

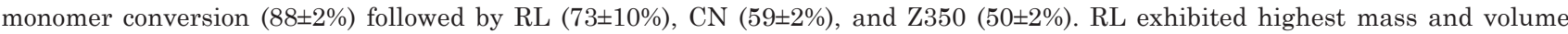
increase (10.22 $\pm 0.04 \mathrm{wt} \%$ and $19.4 \pm 0.2$ vol\%). CN exhibited higher BFS (180 $\pm 20 \mathrm{MPa})$ than RMGICs but lower than Z350 (248 \pm 27 $\mathrm{MPa})$. The highest cumulative fluoride release at 6 weeks was observed with RL (136 $\pm 22 \mathrm{ppm}$ ) followed by CN (36 \pm 4 ppm) and FL $(30 \pm 3 \mathrm{ppm})$. CN exhibited monomer conversion higher than the composite. CN also released fluoride in the range of that observed with RMGICs but with higher flexural strength.
\end{abstract}

Keywords: Monomer conversion, Dimensional stability, Biaxial flexural strength, Fluoride release, Alkaline fillers

\section{INTRODUCTION}

Untreated dental caries is the most prevalent chronic disease affecting 2.4 billion adult and 621 million children worldwide ${ }^{1}$. In 2014 , the cost for management of caries in the US was estimated to be 122 billion USD. The commonly used restorative materials include dental amalgam, resin composites, and glass ionomer cements. Dental amalgam is a cost-effective material but it has been phased down due to the Minamata Convention on Mercury, which is a global treaty to reduce the risk of anthropogenic mercury release to environment ${ }^{2}$. Resin composites showed high mechanical strength ${ }^{3)}$ with superior esthetics compared to dental amalgam. Most of the commercially available composites exhibit no remineralizing effects and require complicated placement techniques. This could increase the risk of bacterial microleakage at the tooth-composite interface leading to secondary caries ${ }^{4)}$ which is the major cause of composite restoration failure. A recently published study demonstrated that secondary caries found in $3.6 \%$ of all restorations and one fifth of the patients experienced at least one secondary caries lesion ${ }^{5)}$. Additionally, the prevalence of secondary caries in composite restorations was almost twice of that in dental amalgam restorations.

GICs exhibit attractive properties such as the ability to release fluoride which could potentially help to promote tooth remineralization and reduce the risk of secondary caries ${ }^{6)}$. Resin-modified glass ionomer cements (RMGICs) has been developed to enable the command setting by photo-polymerization in addition to acid-base neutralization reaction ${ }^{7}$. However, it has been demonstrated that the polymerization of methacrylate monomers may be affected by the restricted radicals mobility from cement hardening through acid-base reaction ${ }^{8)}$. This may reduce early strength and increase the risk of toxic monomer release from RMGICs9). Additionally, low molecular weight and hydrophilic 2-hydroxyethyl methacrylate (HEMA) is used as base monomer in RMGICs. The high flexibility of HEMA polymer may lead to excessive water sorption ${ }^{10)}$ and subsequently reduce mechanical properties of the materials ${ }^{11}$

Recently, a new dual-cured resin based composite containing alkaline fillers (alkasite) has been introduced (Cention N, CN, Ivoclar Vivadent, Schaan, Liechtenstein). The filler phase of this material contains ion-releasing glass fillers (alkaline filler). The liquid phase consists of dimethacrylate monomers which requires hand mixing with filler phase. This material can be cured by light or chemical activated polymerization to facilitate bulk placement.

High monomer conversion of resin-based restorative materials usually associates with high physical/ mechanical properties ${ }^{12}$. The volumetric expansion upon water sorption, i.e. hygroscopic expansion, could potentially help to compensate polymerization shrinkage and relieve shrinkage stress of resin composites ${ }^{13,14)}$. This may subsequently help to reduce the stress generated at tooth-restoration interface that could lead to gap formation and bacterial microleakage. Additionally, water sorption also enabled the release of active components (drugs/ions) from the reactive fillers ${ }^{15,16)}$. Hence, the water sorption may promote the dissolution and diffusion of fluoride from $\mathrm{CN}$ which could potentially help to promote remineralization of tooth structure. The concern was that the absorbed water may cause plasticization of polymer network and detrimentally affect mechanical properties of the material ${ }^{17}$.

The aim of this study was therefore to assess monomer conversion, dimensional stability (hygroscopic expansion), biaxial flexural strength, and fluoride release of the recently developed resin composite containing 
alkaline fillers compared with RMGICs and conventional resin composite.

\section{MATERIALS AND METHODS}

Commercial materials and their compositions used in the study are provided in Table $1^{8,18-20)}$. Materials that require mixing were prepared according to their manufacturer instructions.

\section{Monomer conversion}

An attenuated total reflection-Fourier transform IR (ATRFTIR, Nicolet i5, Thermo Fisher Scientific, Waltham, MA, USA) was employed to assess degree of monomer conversion $\left(D_{c}\right)$ of all materials. The materials were prepared according to their manufacturer instructions $(n=5)$ and were placed in a metal circlip $(10 \mathrm{~mm}$ in diameter and $1 \mathrm{~mm}$ thickness) on the ATR diamond. The specimens were covered by an acetate sheet and light activated by the LED light curing unit (light intensity of 900-1,000 $\mathrm{mW} / \mathrm{cm}^{2}$, DEEP BLUE, SMACO, Hangzhou Zhejiang, China) on the top surface. FTIR spectra in a region of $700-1,800 \mathrm{~cm}^{-1}$ at the bottom surface of the specimens were recorded for $5 \mathrm{~min}$. $D_{c}$ of the sample was then calculated using the following equation. The test was performed at room temperature $\left(25 \pm 1^{\circ} \mathrm{C}\right)$.

$$
D_{c}(\%)=\frac{100\left(\Delta B_{0}-\Delta B_{t}\right)}{\Delta B_{0}}
$$

Equation 1

Where $\Delta B_{0}$ and $\Delta B_{t}$ were the absorbance of the C-O peak $\left(1,320 \mathrm{~cm}^{-1}\right)$ above background level at $1,335 \mathrm{~cm}^{-1}$ initially and after time $t^{21)}$. Peak of $\mathrm{C}=\mathrm{C}$ stretch $(1,637$ $\mathrm{cm}^{-1}$ ) of methacrylate group was not used to calculate degree of monomer conversion because this peak also represents $\mathrm{O}-\mathrm{H}$ stretch of absorbed water in the setting $\mathrm{RMGICs}^{22)}$.

\section{Mass and volume changes}

Gravimetric studies were used to assess mass and volume changes of all materials $(n=3)^{14,21)}$. Disc specimens were prepared $^{14)}$. Materials were prepared according to their manufacturer instruction at room temperature $\left(25 \pm 1^{\circ} \mathrm{C}\right)$. They were placed in a metal circlip $(10 \mathrm{~mm}$ in diameter and $1 \mathrm{~mm}$ in thickness) and covered with an acetate sheet. They were light activated by the LED curing (DEEP BLUE, 900-1,000 $\mathrm{mW} / \mathrm{cm}^{2}$, SMACO) for $40 \mathrm{~s}$ on both top and bottom surfaces and were incubated in an incubator at the controlled temperature of $37^{\circ} \mathrm{C}$ for $1 \mathrm{~h}$. Then, they were removed, trimmed all excess, and placed in a tube containing $10 \mathrm{~mL}$ of deionized water. The tubes were incubated at $37^{\circ} \mathrm{C}$ for up to 4 weeks. At each time points $(0,2,6,24 \mathrm{~h}, 3,4,7$ days, and 2-4 weeks), the samples were removed and blotted dry. Mass and volume of specimens were measured using a fourfigure balance equipped with a density kit (MS-DNY43, METTLER TOLEDO, Columbus, OH, USA). The samples were then placed in the same tube. Mass and volume changes upon immersion time were calculated using the following equations.

$$
\begin{array}{ll}
\Delta M(\%)=\frac{100\left[M_{t}-M_{0}\right]}{M_{0}} & \text { Equation 2 } \\
\Delta V(\%)=\frac{100\left[V_{t}-V_{0}\right]}{V_{0}} & \text { Equation 3 }
\end{array}
$$

\begin{tabular}{|c|c|c|c|}
\hline Materials & Composition & Lot number & Manufacturer \\
\hline $\begin{array}{l}\text { RIVA Light Cure } \\
\text { (RMGIC; RL) }\end{array}$ & $\begin{array}{l}\text { Liquid: Poly(acrylic acid), Tartaric acid, } \\
\text { 2-Hydroxyethyl methacrylate, Dimethacrylate crosslinker, } \\
\text { Acidic monomer } \\
\text { Powder: fluoroalumino silicate glass } \\
\text { Recommended powder to liquid ratio: } 3: 1 \text { (mass ratio) }\end{array}$ & $\begin{array}{l}1096490 \\
\text { (shade A3) }\end{array}$ & $\begin{array}{l}\text { SDI, Bayswater, } \\
\text { Victoria, } \\
\text { Australia }\end{array}$ \\
\hline $\begin{array}{l}\text { Fuji II LC } \\
\text { (RMGIC; FL) }\end{array}$ & $\begin{array}{l}\text { Liquid: Polyacrylic acid, 2-Hydroxyethyl methacrylate } \\
\text { (HEMA), Proprietary ingredient, 2,2,4,-Trimethyl } \\
\text { hexamethylene decarbonate, Triethylene glycol } \\
\text { dimethacrylate } \\
\text { Powder: fluoroalumino silicate glass } \\
\text { Recommended powder to liquid ratio: } 3.2: 1 \text { (mass ratio) }\end{array}$ & $\begin{array}{l}1511141 \\
\text { (shade A3) }\end{array}$ & $\begin{array}{l}\text { GC, } \\
\text { Tokyo, Japan }\end{array}$ \\
\hline $\begin{array}{l}\text { Cention N } \\
\text { (Alkasite; CN) }\end{array}$ & $\begin{array}{l}\text { Liquid: Urethane dimethacrylate, tricyclodecan-dimethanol } \\
\text { dimethacrtylate, polyethylene glycol dimethacrylate } \\
\text { Powder: Inorganic fillers (Ba-Al-Ca-Ba-Al-F silicate glass, } \\
\text { Ca-F-silicate glass, YtF3) and customized fillers } \\
\text { Recommended powder to liquid ratio: 4.6:1 (mass ratio) }\end{array}$ & $\begin{array}{l}\text { W44058 } \\
\text { (shade A2) }\end{array}$ & $\begin{array}{l}\text { Ivoclar Vivadent, } \\
\text { Schaan, } \\
\text { Liechtenstein }\end{array}$ \\
\hline $\begin{array}{l}\text { Filtek } 350 \text { XT } \\
\text { (Resin composite; } \\
\text { Z350) }\end{array}$ & $\begin{array}{l}\text { Urethane dimethacrylate, Bis-GMA, PEGDMA, } \\
\text { Bis-EMA, TEGDMA, zirconia, silica }\end{array}$ & $\begin{array}{l}\text { N834734 } \\
\text { (shade A2) }\end{array}$ & $\begin{array}{l}3 \mathrm{M} \text { ESPE, } \\
\text { St. Pual, } \\
\text { MN, USA }\end{array}$ \\
\hline
\end{tabular}

Table 1 Materials and their compositions used in this study 
Additionally, a modified Fick's equation (equation 4) was employed to calculate a diffusion coefficient $\left(D, \mathrm{~cm}^{2} \mathrm{~s}^{-1}\right)$ of water sorption induced mass change.

$$
\frac{\Delta M_{t}}{\Delta M_{t \rightarrow \infty}}=2 \sqrt{\frac{D_{t}}{\pi d^{2}}}
$$

Equation 4

Where is $\Delta M_{t}$ and $\Delta M_{t \rightarrow \infty}$ are mass increase at time $t$ and maximum increase at time infinity, $d$ is sample thickness (m).

\section{Biaxial flexural strength (BFS) and biaxial flexural} modulus (BFM)

The ball-on-ring testing jig were used to measured BFS and BFM of the tested materials $(n=8)^{21)}$. Disc specimens were prepared according to section 2.2 and immersed in a tube containing $10 \mathrm{~mL}$ of deionized water. The tubes were incubated at $37^{\circ} \mathrm{C}$ for $24 \mathrm{~h}$ prior the test. Thicknesses of the specimens were measured using a digital vernier calliper and placed on a ring support (8 $\mathrm{mm}$ in diameter) of the ball-on-ring testing jig. BFS of the specimens was determined at room temperature $\left(25 \pm 1^{\circ} \mathrm{C}\right)$ using mechanical testing frame (AGSX, Shimadzu, Kyoto, Japan) using 500 N load cell with a crosshead speed of $1 \mathrm{~mm} / \mathrm{min}$. The load was applied using a ball indenter (4 $\mathrm{mm}$ in diameter). BFS (S; Pa) was calculated using the following equation.

$$
\mathrm{S}=\frac{F}{d^{2}}\left\{(1+v)\left[0.485 \ln \left(\frac{r}{d}\right)+0.52\right]+0.48\right\} \quad \text { Equation } 5
$$

Where $F$ is the load at failure $(\mathrm{N}), d$ is the specimen's thickness $(\mathrm{m}), r$ is the radius of circular support $(\mathrm{m})$, and $v$ is Poison's ratio (0.3). Additionally, BFM was calculated using the following equation.

$$
E=\left(\frac{\Delta H}{\Delta W_{c}}\right) \times\left(\frac{\beta_{c} d^{2}}{q^{3}}\right)
$$

Equation 6

Where $E$ is BFM of the specimen $(\mathrm{Pa}), \frac{\Delta H}{\Delta W_{c}}$ is rate of change of load with regards to central deflection or gradient of force versus displacement curve $(\mathrm{N} / \mathrm{m}), \beta_{c}$ is center deflection junction $(0.5024)^{23)}, q$ is ratio of support radius to the radius of disc, and $v$ is Poison's ratio (0.3).

\section{Fluoride release}

Disc specimens were prepared according to section 2.2 and placed in a tube containing $5 \mathrm{~mL}$ of deionized water. The tubes were incubated at the controlled temperature of $37^{\circ} \mathrm{C}$ for up to 6 weeks. At each time point (1-5 days and 1-6 weeks), the storage solution was collected and replaced with a fresh solution. The collected solution was mixed with TISAB III solution (Orion Ionplus, Thermo Fisher Scientific) with a ratio of 1:10 (volume ratio). Fluoride calibration standards (0.1, 1, 10, 100 Fppm) were prepared using a standard fluoride solution (Orion Ionplus, Thermo Fisher Scientific). Fluoride ion concentration in the solution was then measured using fluoride specific ion electrode (Orion Versastar Pro,
Thermo Fisher Scientific). The cumulative fluoride ion release was calculated using the following equation.

$$
F_{c}=\Sigma_{0}^{t} F_{t}
$$

Equation 7

Where $F_{c}$ is the cumulative fluoride ion release (ppm), $F_{t}$ is the amount of fluoride (ppm) at time $t$.

\section{Statistical analysis}

Data reported in this study was mean and 95\% confidence interval $(95 \% \mathrm{CI})$. Data was then analyzed using SPSS for Window version 25 (IBM, Armonk, NY, USA). Levene's test was used to assess the homogeneity of variances of results. One-way ANOVA followed by posthoc Tukey multiple comparison was used if variances between materials were equal. Dunnett T3 post-hoc multiple comparison was used when the variances were not equal. Additionally, post hoc power analysis was performed using G*Power 3.1 Software (University of Dusseldorf, Germany). The results confirmed that the sample size of each test gave power $>0.99$ at $\alpha=0.05$.

\section{RESULTS}

\section{Monomer conversion}

The highest monomer conversion was observed with FL ( $88 \pm 2 \%)$ followed by RL $73 \pm 10 \%)$, CN (59 $\pm 2 \%)$, and Z350 $(50 \pm 2 \%)$ respectively (Fig, 1$)$. All results are significantly different from each other $(p<0.05)$.

\section{Mass and volume changes}

Mass of RL and FL increased linearly with square root of hour for up to $24 \mathrm{~h}$ then reached plateau at $10.22 \pm 0.04$ and 3.96 $\pm 0.12 \mathrm{wt} \%$, respectively. Mass of Z350 increased slightly to $0.79 \pm 0.10 \mathrm{wt} \%$ at 1 week then levelling off. Mass of $\mathrm{CN}$ increased to $0.07 \pm 0.05$ wt $\%$ at 1 week then gradually decreased and became negative. The average mass change of $\mathrm{CN}$ at 2-4 weeks was $-0.28 \pm 0.05 \mathrm{wt} \%$. Volume changes of RL and FL increased linearly for up

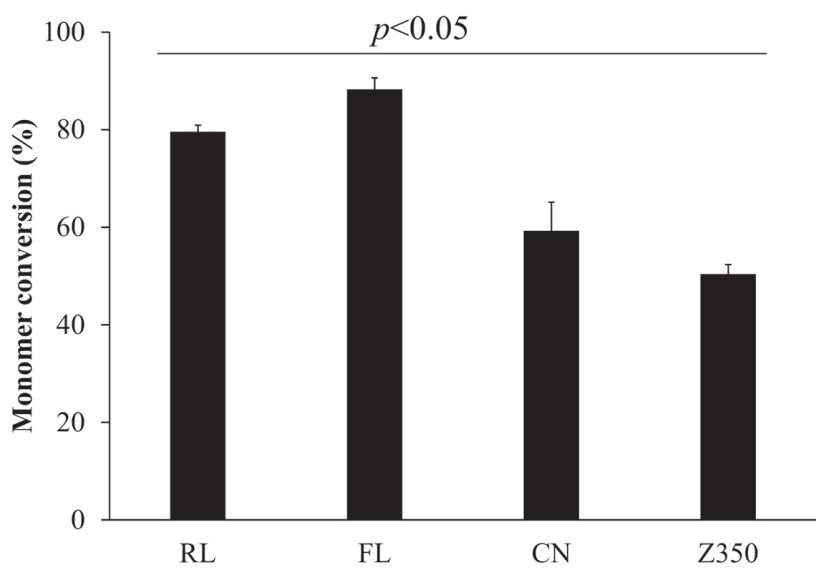

Fig. 1 Monomer conversion after light cured of all materials tested at room temperature $\left(25^{\circ} \mathrm{C}\right)$. Error bars are 95\%CI $(n=5)$. 

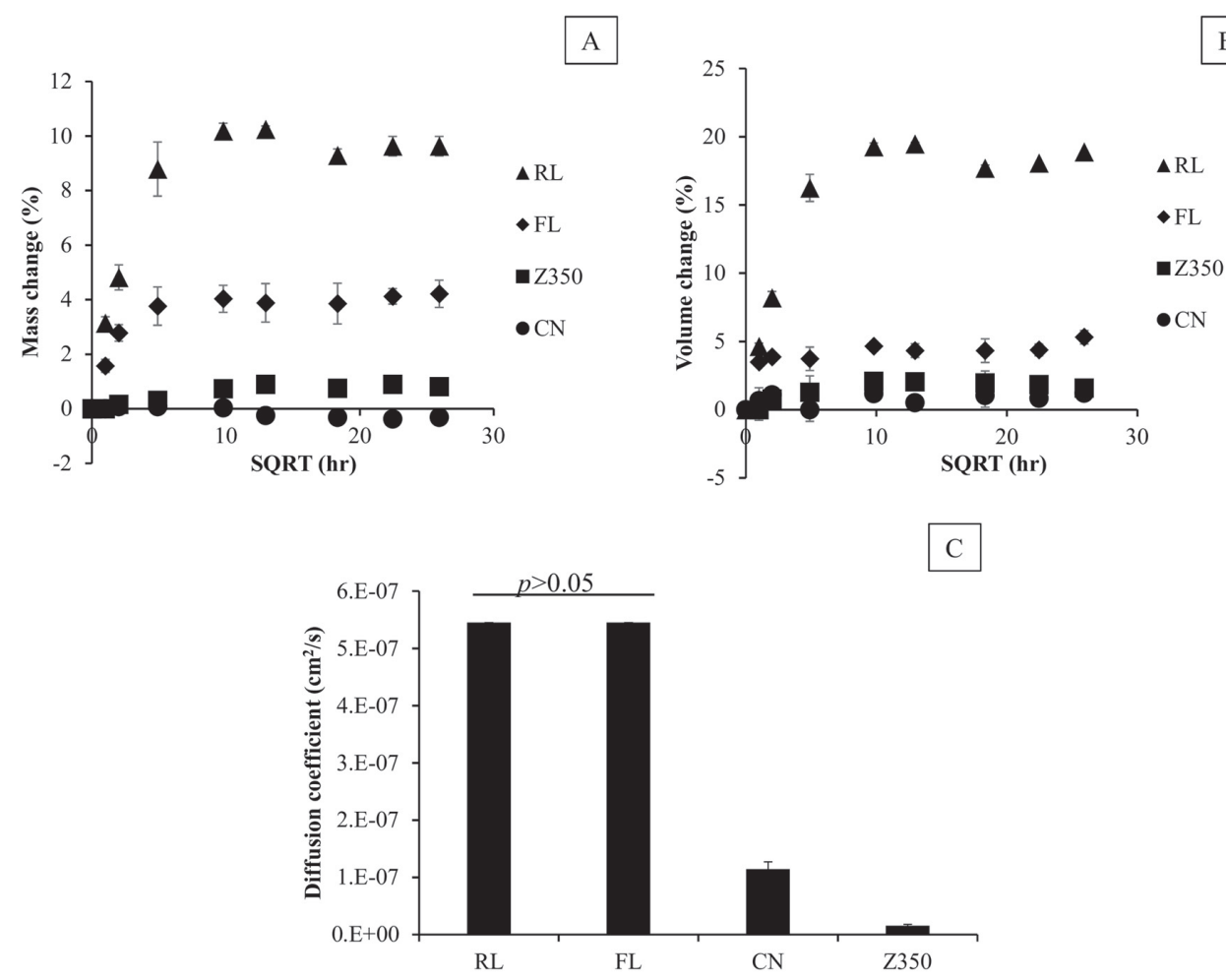

Fig. 2 A) Mass and B) volume changes plotted against square root of hour of all materials upon immersion in deionized water for up to 4 weeks. C) Diffusion coefficient of water sorption induced mass change of all materials.

Error bars are $95 \% \mathrm{CI}(n=3)$.
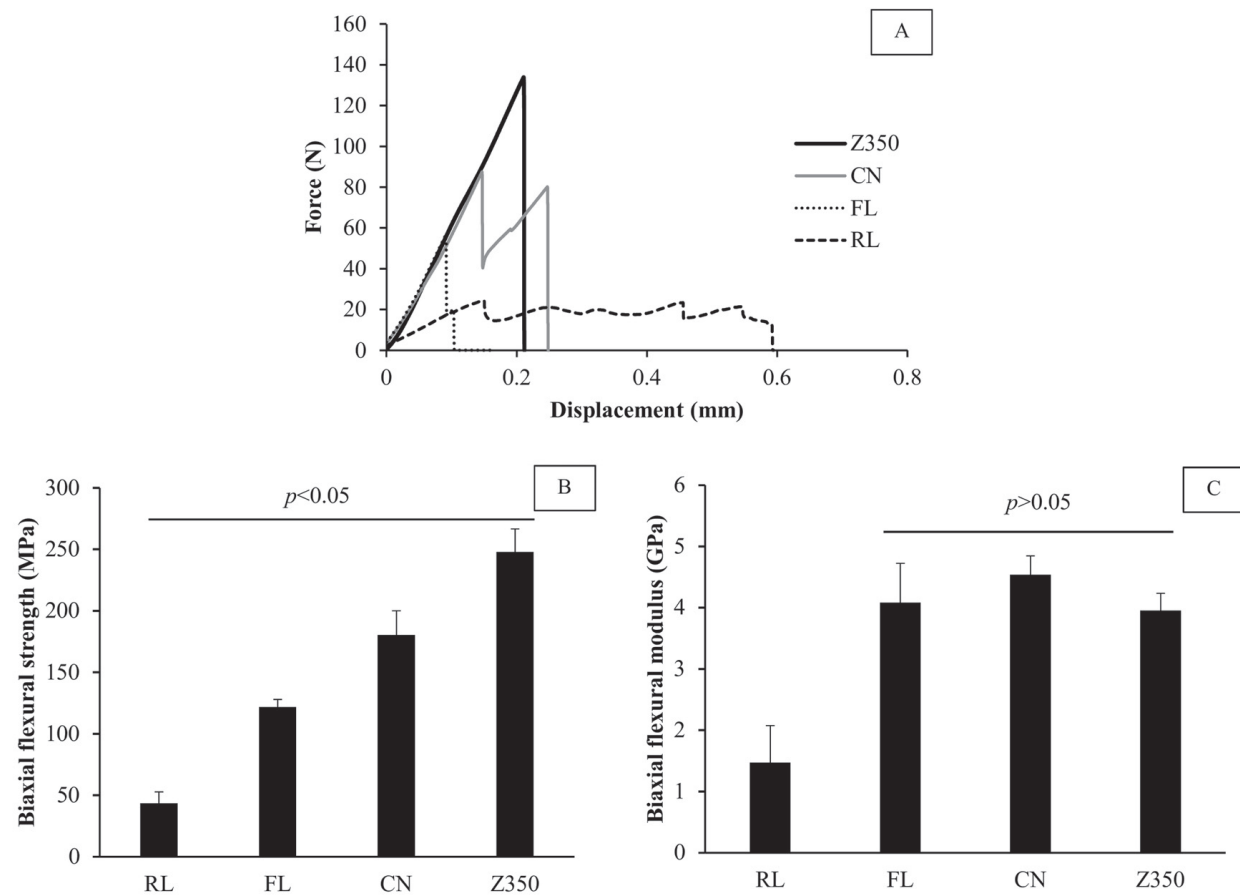

Fig. 3 A) Examples force versus displacement curves of all materials. B) BFS and C) BFM of all materials after immersion in deionized water for $24 \mathrm{~h}$.

Error bars are $95 \% \mathrm{CI}(n=8)$. 

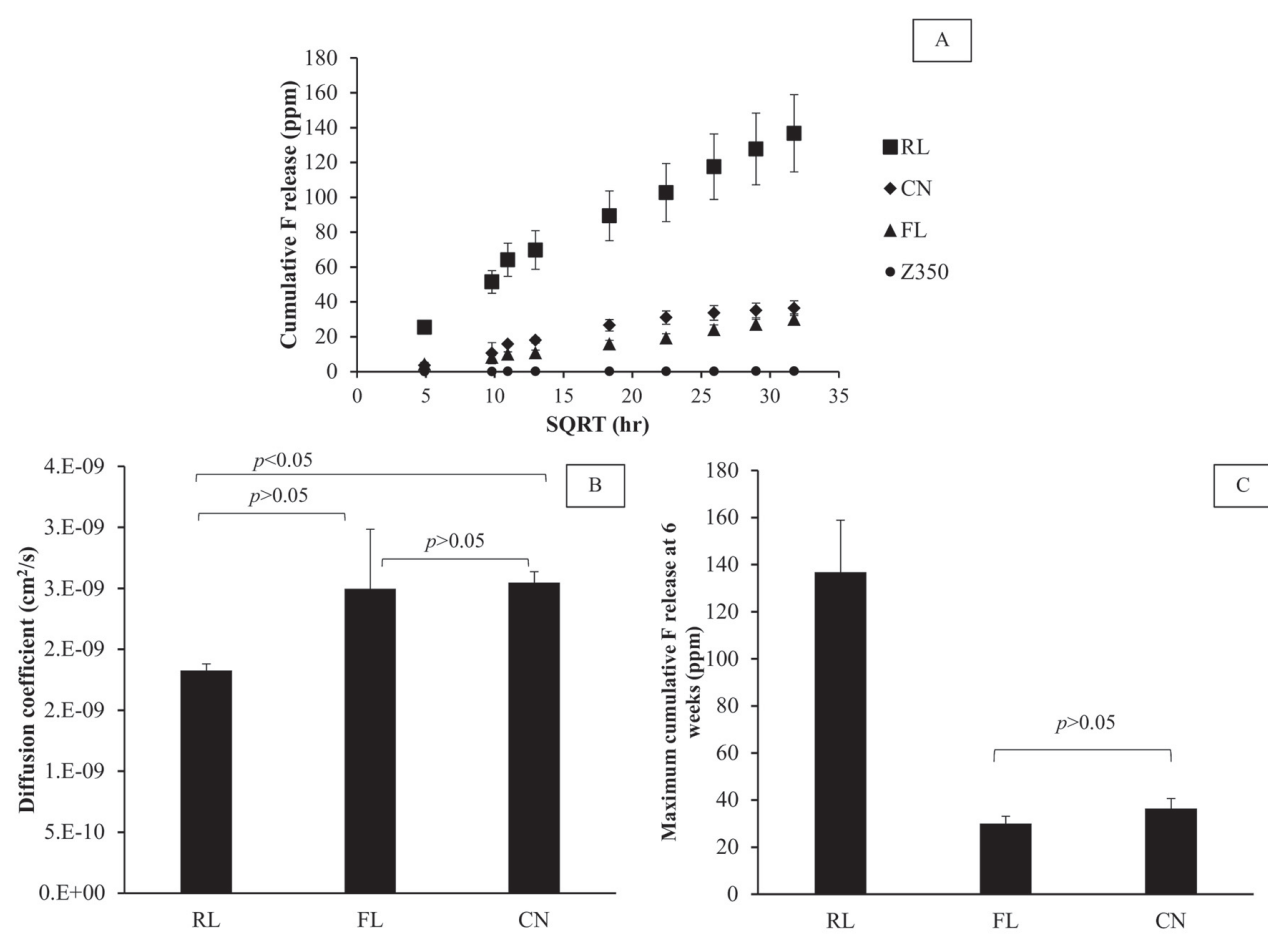

Fig. 4 A) fluoride release in deionized water for up to 6 weeks. B) Diffusion coefficient of fluoride for up 1 week. C) Cumulative release of fluoride at 6 weeks.

Error bars are $95 \% \mathrm{CI}(n=3)$.

to 1 week then levelling off. The average volume change at 2-4 weeks of RL and FL were $19.4 \pm 0.2$ and $4.5 \pm 0.3$ vol\%, respectively. The average volume change at late time of $\mathrm{Z} 350$ and $\mathrm{CN}$ were $2.0 \pm 0.1$ and $0.8 \pm 0.5$ vol\%, respectively.

The diffusion coefficient of water sorption induced mass change observed with $\mathrm{RL}\left(5.5 \times 10^{-7} \pm 1.2 \times 10^{-11} \mathrm{~cm}^{2} / \mathrm{s}\right)$ was comparable with that of Fuji II LC $\left(5.5 \times 10^{-7} \pm 1.1 \times 10^{-11}\right.$ $\left.\mathrm{cm}^{2} / \mathrm{s}\right)(p=0.275)$. The diffusion coefficient of both RL and FL were however significantly higher than that of $\mathrm{CN}$ $\left(1.1 \times 10^{-7} \pm 1.5 \times 10^{-8} \mathrm{~cm}^{2} / \mathrm{s}\right)$ and Z350 $\left(1.5 \times 10^{-8} \pm 2.6 \times 10^{-9}\right.$ $\left.\mathrm{cm}^{2} / \mathrm{s}\right)(p<0.05)$ (Fig. 2C).

\section{$B F S$ and BFM}

All materials except for RL showed a rapid increase of applied force then reached maximum or breaking point within the displacement range of $0.3 \mathrm{~mm}$ (Fig. 3A). For RL, the maximum force was maintained for up to displacement of $0.6 \mathrm{~mm}$ before reaching the breaking point. The highest BFS was observed with Z350 (248 \pm 27 $\mathrm{MPa})$ followed by $\mathrm{CN}(180 \pm 20 \mathrm{MPa}), \mathrm{FL}(122 \pm 6 \mathrm{MPa})$, and RL (43 $\pm 9 \mathrm{MPa}$ ) (Fig. 3B). The BFM of CN (4.5 \pm 0.3 $\mathrm{GPa}), \mathrm{FL}(4.1 \pm 0.6 \mathrm{GPa})$, and $\mathrm{Z} 350(4.0 \pm 0.3 \mathrm{GPa})$ were comparable $(p>0.05$, Fig. $3 \mathrm{C})$. BFM of these three materials were significantly higher than that of $\mathrm{RL}$ $(1.5 \pm 0.6 \mathrm{GPa}, p<0.05)$.

\section{Fluoride release}

Fluoride ions was not detected from the storage solution of Z350. At 1 day, RL, FL, and CN exhibited a burst fluoride release of $25.4 \pm 3.1,4.3 \pm 0.6$, and $4.4 \pm 0.8 \mathrm{ppm}$, respectively (Fig. 4A). Fluoride release of all materials, except for $\mathrm{CN}$, increased linearly with square root of time (h) up to the end of measurement (6 weeks). Fluoride release of $\mathrm{CN}$, however, began to level off at 4 weeks. The highest diffusion coefficient of fluoride was observed with $\mathrm{CN}\left(2.6 \times 10^{-9} \pm 9.8 \times 10^{-11} \mathrm{~cm}^{2} / \mathrm{s}\right)$ followed by FL $\left(2.5 \times 10^{-9} \pm 4.9 \times 10^{-10} \mathrm{~cm}^{2} / \mathrm{s}\right)$ and RL $\left(1.8 \times 10^{-9} \pm 3.3 \times 10^{-11}\right.$ $\mathrm{cm}^{2} / \mathrm{s}$ ) (Fig. 4B). The cumulative fluoride release at 6 weeks of RL ( $137 \pm 22 \mathrm{ppm})$ was significantly higher than that of $\mathrm{CN}(37 \pm 4 \mathrm{ppm}, p=0.024)$ and FL (30 $\pm 3 \mathrm{ppm}$, $p=0.021)$ (Fig. 4C).

\section{DISCUSSION}

\section{Monomer conversion}

The degree of monomer conversion of polymer-based filling materials was primarily governed by chemical structure of monomers ${ }^{24)}$, polymerization environments $^{25)}$, and thickness of the specimens ${ }^{26)}$. High monomer conversion of resin-based restorative materials is required to ensure good physical properties and cytocompatibility of the materials ${ }^{27,28)}$. The minimum degree of monomer conversion required from resinbased materials is not yet established. It is however demonstrated that composites with the conversion lower than 55-65\% exhibited low abrasive resistance ${ }^{29}$. It is also proposed that composites with monomer conversion lower than $55 \%$ may not suitable for occlusal restorative layers ${ }^{30)}$. 
The monomer conversion of FL, CN, and Z350 obtained from the current study were comparable with that reported in published studies ${ }^{22,31}$. In general, monomers with lower glass transition temperature $\left(T_{g}\right)$ showed higher degree of monomer conversion than monomers with higher $T_{g}^{24)}$. The primary base monomer contained in FL and RL is 2-hydroxyethyl methacrylate (HEMA, $\left.T_{g}=-60^{\circ} \mathrm{C}\right)^{24,32}$. For CN and Z350, their primary base monomer is urethane dimethacrylate (UDMA, $T_{g}=-35^{\circ} \mathrm{C}$ ) and bisphenol A-glycidyl methacrylate (BisGMA, $T_{g}=-7.7^{\circ} \mathrm{C}$ ) respectively. Hence, high monomer conversion was observed with FL and RL which was greater than that of $\mathrm{CN}$ and Z350. Furthermore, the recommended powder to liquid ratio (PLR) of CN (PLR 4.6:1) was higher than that of RL (PLR 3:1) and FL (PLR 3.2:1). The high PLR may lead to high viscosity of the polymerizing mixture of $\mathrm{CN}$. This may limit the mobility of free radicals which could subsequently reduce the rate of polymerization of the material ${ }^{25}$.

The current study measured monomer conversion after light curing for $5 \mathrm{~min}$ to represent the level of monomer conversion initially after placement. It is however known that degree of monomer conversion can be increased slightly until $24 \mathrm{~h}^{33}$. It is therefore expected that final monomer conversion of all products can potentially increase to enhance their physical and mechanical properties.

\section{Mass and volume changes}

Water are required for acid-base neutralization of GICs setting reaction. Furthermore, the absorbed water also enables release of ions from hydrophilic/reactive fillers. The water sorption induced expansion of polymer-based materials could be governed primarily by the flexibility of polymer matrix and the addition of hydrophilic components ${ }^{14,16,21)}$.

Low diffusion coefficient of water sorption induced expansion observed in $\mathrm{CN}$ and Z350 could be due to the high rigidity of UDMA and Bis-GMA polymer network in both $\mathrm{CN}$ and Z350 which may limit water sorption resulting in the low mass and volume changes ${ }^{21}$. High mass and volume increase observed with RMGICs (RL and FL) could be due primarily to their hydrophilic and flexible HEMA polymer and polyacrylic salts network facilitating diffusion of water into materials ${ }^{34}$.

Excessive water sorption may cause the decline in mechanical properties of restorative materials ${ }^{17)}$. It is however demonstrated that water sorption induced volume expansion could potentially help to compensate polymerization shrinkage and relieve shrinkage stress ${ }^{13)}$. Mass and volume increase observed with Z350 and CN were in the range of results obtained from conventional resin composites in published studies $(\sim 1 \mathrm{wt} \%$ and $\sim 2$ vol\%) ${ }^{26,35)}$. However, the loss of mass was observed with $\mathrm{CN}$ which could be due to the release of soluble species from reactive fillers. The similar result was obtained in the experimental resin composites containing soluble reactive fillers ${ }^{21,36)}$.

\section{BFS and modulus of elasticity}

Restorative materials should exhibit high flexural strength to ensure that the materials can function under occlusal loads ${ }^{37}$. It has been demonstrated that BFS test yielded comparable strength to three-point bending test but the result can be reproducible ${ }^{38}$. The result from the current study indicated that only Z350 and CN exhibited flexural strength greater that required from the ISO $4049(80 \mathrm{MPa})^{39}$. The flexural strength of RMGICs (RL and FL) was also greater than $25 \mathrm{MPa}$ required by the ISO 9917-2:2017 Dentistry-Water-based cements (Part 2: Resin-modified cements ${ }^{40}$. RL exhibited lower strength than FL which could be due to the highest hygroscopic expansion. This may increase solubility and subsequently reduce strength of the materials. The flexural strength and flexural modulus of $\mathrm{CN}$ also in the range of values obtained from the hybrid resin composites (100-161 MPa and 6-10 GPa ${ }^{26,411}$.

Lowest BFS was observed with RL. The forcedisplacement curve of RL revealed the less brittle and more plastic behaviour compared with other materials. This could be due to high water sorption induce plasticization of resin matrix ${ }^{17}$. This could detrimentally affect mechanical properties of the materials.

FL exhibited comparable modulus to $\mathrm{CN}$ and Z350 but the strength of FL was lower than both $\mathrm{CN}$ and Z350. The possible explanation could be that the low level of water sorption induced hygroscopic expansion observed in FL led to the low solubility of specimens and the incomplete acid-base reaction. This may increase the amount of the unreacted glass fillers that act as the reinforcing phase in GICs. This partially reacted fillers may therefore attribute to the high stiffness of FL which was in the range of that obtained from $\mathrm{CN}$ and Z350. However, $\mathrm{CN}$ is resin-based composite containing high $T_{g}$ monomers that provide high flexural strength such as Bis-GMA or UDMA reinforced with glass fillers ${ }^{12,42}$. The strength of $\mathrm{CN}$ was therefore expected to be in the range of that observed with resin composites which was usually higher than that of RMGICs ${ }^{3)}$. Z350 exhibited the highest flexural strength as was expected due primarily to the use of high $T_{g}$ monomers dispersed with high nanofiller contents in the material. The presence of these closely spaced disperse fillers may increase the strength and fracture energy of resin composites ${ }^{43}$. Furthermore, $\mathrm{CN}$ contains alkaline filler (Ca-F-Si glass fillers) which may react with water and release ions from the material. The dissolution of the fillers may consequently reduce mechanical properties of $\mathrm{CN}$.

\section{Fluoride release}

It is expected that the released fluoride ions may help to reduce the risk of tooth demineralization by promoting the formation of low soluble fluorohydroxyapatite ${ }^{44}$. Additionally, fluoride can inhibit bacterial metabolism which may help to reduce bacterial growth ${ }^{45}$. Diffusioncontrolled release of active ingredients is usually observed in polymer-based restorative materials ${ }^{7}$. The current study showed that fluoride release in deionized water of all materials except for Z350 increased linearly 
with square root of time indicating a diffusion-controlled release. This can be demonstrated by the modified Fickian equation.

$$
\Delta F=\Delta F_{0}+\Delta F_{\infty} \sqrt{\frac{2 D_{t}}{\pi d^{2}}}
$$

Equation 8

Where $\Delta F$; the change in cumulative fluoride in the solution, $\Delta F_{0}$; early burst release, $\Delta F_{\infty} ;$ maximum change in the solution, $D$; fluoride diffusion coefficient, $t$; time, $d$; sample thickness. Fluoride release from GICs is mainly controlled by the composition of materials, powder to liquid ratio, solubility of glass particles, rate of acid neutralization, water sorption, and the initial concentration of fluoride that contained in the materials ${ }^{22)}$.

The possible explanation of high concentration of fluoride release observed with RL could be high water sorption promoting acid-neutralization reaction and release fluoride ion from fluoro-alumino-silicate glass. This high level of fluoride release from RL could be of benefit to promote remineralization and the formation of low soluble fluorohydroxyapatite in tooth surface. This could potentially help to reduce the risk of tooth demineralization due to bacterial microleakage leading to secondary caries, which is the major cause of composite restoration failure ${ }^{46)}$. CN showed comparable fluoride diffusion coefficient and releasing profile to FL. This could be due to the low monomer conversion and low crosslinking density in the polymer network of $\mathrm{CN}$ which may facilitate the diffusion of fluoride. Additionally, the mixing of $\mathrm{CN}$ required higher PLR than that of RL and FL. This high PLR may increase the risk of air entrapment during mixing. The pores generated due to air incorporation could also facilitate the diffusion of fluoride ${ }^{47,48)}$.

In summary, RMGICs (RL,FL) showed higher monomer conversion than Z350 and CN due to the use of low molecular weight monomer (HEMA) as the primary base monomer. The hydrophilicity of HEMA polymer may increase water sorption to plasticize resin matrix thereby reducing strength of the materials. This may increase the risk of restoration fracture in load-bearing areas which was the main cause of GICs restoration failure ${ }^{49)}$. The flexural strength of $\mathrm{CN}$ and FL were lower than that of Z350 but still in the acceptable range of the ISO standard for resin composite. CN and FL can, however, exhibit fluoride release which could potentially help to reduce the risk of secondary caries.

\section{CONCLUSION}

Monomer conversion of $\mathrm{CN}$ was higher than that of Z350 but lower than that of FL and RL. CN and Z350 showed lower mass and volume changes (good dimensional stability) and higher BFS than FL and RL. However, CN exhibited lower BFS than Z350 but can release fluoride in the range of that observed with FL.

\section{ACKNOWLEDGMENTS}

The authors would like to express their heartfelt gratitude to Faculty of Dentistry, Thammasat University for providing the grant to conduct this research (grant ID: $1 / 2560)$.

\section{CONFLICTS OF INTEREST}

The authors report no conflicts of interest.

\section{REFERENCES}

1) Kassebaum NJ, Bernabe E, Dahiya M, Bhandari B, Murray CJ, Marcenes W. Global burden of untreated caries: a systematic review and metaregression. J Dent Res 2015; 94 : 650-658

2) Mackey TK, Contreras JT, Liang BA. The Minamata Convention on Mercury: attempting to address the global controversy of dental amalgam use and mercury waste disposal. Sci Total Environ 2014; 472: 125-129.

3) Ilie N, Hickel R, Valceanu AS, Huth KC. Fracture toughness of dental restorative materials. Clin Oral Investig 2012; 16: 489-498.

4) Nedeljkovic I, Teughels W, De Munck J, Van Meerbeek B, Van Landuyt KL. Is secondary caries with composites a material-based problem? Dent Mater 2015; 31: e247-277.

5) Nedeljkovic I, De Munck J, Vanloy A, Declerck D, Lambrechts $\mathrm{P}$, Peumans $\mathrm{M}$, et al. Secondary caries: prevalence, characteristics, and approach. Clin Oral Investig 2020; 24: 683-691.

6) Sidhu SK. Glass-ionomer cement restorative materials: a sticky subject? Aust Dent J 2011; 56 Suppl 1: 23-30.

7) Sidhu SK, Nicholson JW. A review of glass-Ionomer cements for clinical dentistry. J Funct Biomater 2016; 7: E16.

8) Dursun E, Nguyen JF, Tang ML, Attal JP, Sadoun M. HEMA release and degree of conversion from a resin-modified glass ionomer cement after various delays of light activation. Dent Mater 2016; 32: 640-645.

9) dos Santos RL, Pithon MM, Martins FO, Romanos MT, Ruellas AC. Evaluation of cytotoxicity and degree of conversion of glass ionomer cements reinforced with resin. Eur J Orthod 2012; 34: 362-366.

10) Mehdawi IM, Pratten J, Spratt DA, Knowles JC, Young AM. High strength re-mineralizing, antibacterial dental composites with reactive calcium phosphates. Dent Mater 2013; 29: 473-484.

11) Yoda A, Nikaido T, Ikeda M, Sonoda H, Foxton RM, Tagami J. Effect of curing method and storage condition on fluoride ion release from a fluoride-releasing resin cement. Dent Mater J 2006; 25: 261-266.

12) Barszczewska-Rybarek I, Jurczyk S. Comparative study of structure-property relationships in polymer networks based on Bis-GMA, TEGDMA and various urethane-dimethacrylates. Materials (Basel) 2015; 8: 1230-1248.

13) Suiter EA, Watson LE, Tantbirojn D, Lou JS, Versluis A. Effective expansion: balance between shrinkage and hygroscopic expansion. J Dent Res 2016; 95: 543-549.

14) Kangwankai K, Sani S, Panpisut P, Xia W, Ashley P, Petridis $\mathrm{H}$, et al. Monomer conversion, dimensional stability, strength, modulus, surface apatite precipitation and wear of novel, reactive calcium phosphate and polylysine-containing dental composites. PLoS One 2017; 12: e0187757.

15) Garoushi S, Vallittu PK, Lassila L. Characterization of fluoride releasing restorative dental materials. Dent Mater J 2018; 37: 293-300.

16) Panpisut P, Khan MA, Main K, Arshad M, Xia W, Petridis H, 
et al. Polymerization kinetics stability, volumetric changes, apatite precipitation, strontium release and fatigue of novel bone composites for vertebroplasty. PLoS One 2019; 14: e0207965.

17) Ferracane JL. Hygroscopic and hydrolytic effects in dental polymer networks. Dent Mater 2006; 22: 211-222.

18) Okulus Z, Buchwald T, Voelkel A. Characterization of lightcured, dental-resin-based biocomposites. J Appl Polym Sci $2015 ; 132$.

19) Ilie N. Comparative effect of self- or dual-curing on polymerization kinetics and mechanical properties in a novel, dental-resin-based composite with alkaline filler. Materials (Basel) 2018; 11: 108 .

20) Miotti LL, Santos IS, Nicoloso GF, Pozzobon RT, Susin AH, Durand LB. The use of resin composite layering technique to mask discolored background: A CIELAB/CIEDE2000 Analysis. Oper Dent 2017; 42: 165-174.

21) Panpisut P, Liaqat S, Zacharaki E, Xia W, Petridis H, Young AM. Dental composites with calcium/trontium phosphates and polylysine. PLoS One 2016; 11: e0164653.

22) Young AM. FTIR investigation of polymerisation and polyacid neutralisation kinetics in resin-modified glass-ionomer dental cements. Biomaterials 2002; 23: 3289-3295.

23) Higgs WA, Lucksanasombool P, Higgs RJ, Swain MV. A simple method of determining the modulus of orthopedic bone cement. J Biomed Mater Res 2001; 58: 188-195.

24) Sideridou I, Tserki V, Papanastasiou G. Effect of chemical structure on degree of conversion in light-cured dimethacrylate-based dental resins. Biomaterials 2002; 23: 1819-1829.

25) Habib E, Wang R, Zhu XX. Correlation of resin viscosity and monomer conversion to filler particle size in dental composites. Dent Mater 2018; 34: 1501-1508.

26) Aljabo A, Xia W, Liaqat S, Khan M, Knowles J, Ashley P, et al. Conversion, shrinkage, water sorption, flexural strength and modulus of re-mineralizing dental composites. Dent Mater 2015; 31: 1279-1289.

27) Kurt A, Altintas SH, Kiziltas MV, Tekkeli SE, Guler EM, Kocyigit A, et al. Evaluation of residual monomer release and toxicity of self-adhesive resin cements. Dent Mater J 2018; 37: 40-48.

28) Grohmann CVS, Soares EF, Souza-Junior EJC, Brandt WC, Puppin-Rontani RM, Geraldeli S, et al. Influence of different concentration and ratio of a photoinitiator system on the properties of experimental resin composites. Braz Dent $\mathrm{J}$ 2017; 28: 726-730.

29) Ferracane JL, Mitchem JC, Condon JR, Todd R. Wear and marginal breakdown of composites with various degrees of cure. J Dent Res 1997; 76: 1508-1516.

30) Silikas N, Eliades G, Watts DC. Light intensity effects on resin-composite degree of conversion and shrinkage strain. Dent Mater 2000; 16: 292-296.

31) Goncalves F, Campos LMP, Rodrigues-Junior EC, Costa FV, Marques PA, Francci CE, et al. A comparative study of bulkfill composites: degree of conversion, post-gel shrinkage and cytotoxicity. Braz Oral Res 2018; 32: e17.

32) Achilias DS, Siafaka PI. Polymerization kinetics of poly(2hydroxyethyl methacrylate) hydrogels and nanocomposite materials. Processes 2017; 5: 21.

33) Alshali RZ, Silikas N, Satterthwaite JD. Degree of conversion of bulk-fill compared to conventional resin-composites at two time intervals. Dent Mater 2013; 29: e213-e217.

34) Yiu CK, King NM, Carrilho MR, Sauro S, Rueggeberg FA, Prati C, et al. Effect of resin hydrophilicity and temperature on water sorption of dental adhesive resins. Biomaterials 2006; 27: 1695-1703.

35) Alshali RZ, Salim NA, Satterthwaite JD, Silikas N. Longterm sorption and solubility of bulk-fill and conventional resin-composites in water and artificial saliva. J Dent 2015; 43: 1511-1518.

36) Par M, Spanovic N, Bjelovucic R, Marovic D, Schmalz G, Gamulin $\mathrm{O}$, et al. Long-term water sorption and solubility of experimental bioactive composites based on amorphous calcium phosphate and bioactive glass. Dent Mater J 2019; 38: 555-564.

37) Heintze SD, Ilie N, Hickel R, Reis A, Loguercio A, Rousson V. Laboratory mechanical parameters of composite resins and their relation to fractures and wear in clinical trials-A systematic review Siegward. Dent Mater 2017; 33: E101E114.

38) Pick B, Meira JB, Driemeier L, Braga RR. A critical view on biaxial and short-beam uniaxial flexural strength tests applied to resin composites using Weibull, fractographic and finite element analyses. Dent Mater 2010; 26: 83-90.

39) British Standard. BS EN ISO 4049:2009 Dentistry. Polymerbased restorative materials. Switzerland: BSI Standards Limited; 2009.

40) British Standard. ISO 9917-2:2017. Dentistry —Water-based cements Part 2: Resin-modified cements (ISO 9917-2:2017). Switzerland: BSI Standards Limited; 2017.

41) Ilie N, Hickel R. Investigations on mechanical behaviour of dental composites. Clin Oral Investig 2009; 13: 427-438.

42) Gajewski VES, Pfeifer CS, Fróes-Salgado NRG, Boaro LCC, Braga RR. Monomers used in resin composites: degree of conversion, mechanical properties and water sorption/ solubility. Braz Dent J 2012; 23: 508-514.

43) Rodrigues SA Jr, Scherrer SS, Ferracane JL, Della Bona A. Microstructural characterization and fracture behavior of a microhybrid and a nanofill composite. Dent Mater 2008; 24: 1281-1288.

44) Tantbirojn D, Feigal RJ, Ko CC, Versluis A. Remineralized dentin lesions induced by glass ionomer demonstrate increased resistance to subsequent acid challenge. Quintessence Int 2006; 37: 273-281.

45) Buzalaf MA, Pessan JP, Honorio HM, ten Cate JM. Mechanisms of action of fluoride for caries control. Monogr Oral Sci 2011; 22: 97-114.

46) Kopperud SE, Tveit AB, Gaarden T, Sandvik L, Espelid I. Longevity of posterior dental restorations and reasons for failure. Eur J Oral Sci 2012; 120: 539-548.

47) Mousavinasab SM, Meyers I. Fluoride release by glass ionomer cements, compomer and giomer. Dent Res J (Isfahan) 2009; 6: 75-81.

48) Cabral MF, Martinho RL, Guedes-Neto MV, Rebelo MA, Pontes DG, Cohen-Carneiro F. Do conventional glass ionomer cements release more fluoride than resin-modified glass ionomer cements? Restor Dent Endod 2015; 40: 209-215.

49) van Dijken JWV, Pallesen U. Fracture frequency and longevity of fractured resin composite, polyacid-modified resin composite, and resin-modified glass ionomer cement class IV restorations: an up to 14 years of follow-up. Clin Oral Investig 2010; 14: 217-222. 